Fulton, J. D. \& Rimington, C. (1953). J. gen. Microbiol. 8, 157-159.

\title{
The Pigment of the Malaria Parasite Plasmodium berghei
}

\author{
By J. D. FULTON and C. RIMINGTON \\ National Institute for Medical Research, Mill Hill, London, N.W.7., \\ and Department of Chemical Pathology, University College Hospital Medical \\ School, London, W.C.1
}

\begin{abstract}
SUMMARY: The pigment of Plasmodium berghei, a recently discovered parasite of a wild rodent, Thamnomys surdaster, in the Belgian Congo, has been isolated from the infected red cells of young rats in which the strain is maintained in the laboratory. It has been shown by chemical and spectroscopical evidence to be haematin.
\end{abstract}

Early work by Brown (1911) indicated that the pigment occurring in the spleen and liver of malarial patients infected with Plasmodium falciparum, the parasite of malignant tertian malaria, was haematin. Sinton \& Ghosh $(1934 a, b)$ and Ghosh \& Sinton (1934) extracted the pigment from the red cells of monkeys heavily parasitized with $P$. knowlesi and established that this substance was closely similar to or identical with haematin. Devine \& Fulton (1941) and Morrison \& Anderson (1942) presented further data in support of the nature of this monkey pigment. From spectroscopic and other evidence, that present in $P$. gallinaceum of chickens was also shown by Devine \& Fulton (1942) to be haematin. Because the above authors used dilute alkali for extraction, which is known to bring about changes in the properties of this substance, Rimington $\&$ Fulton (1947) reinvestigated the pigment of $\boldsymbol{P}$. knowlesi and of $\boldsymbol{P}$.gallinaceum using concentrated phenol for extraction, and established beyond reasonable doubt that the vinyl side chains in the haematin remained unaffected. Recently a plasmodium, which parasitizes the wild rodent Thamnomys surdaster in the Congo, has been described by Vincke \& Lips (1948) and named by them Plasmodium berghei. It readily infects mice, rats, hamsters and other laboratory animals, and has proved useful in chemotherapeutic experiments. This note describes a chemical investigation of the pigment present within the parasite.

\section{Experimental}

Hooded rats of weight $60-80 \mathrm{~g}$. were inoculated intraperitoneally with infected blood from a donor rat and 1 week later, when the infection had reached a peak, the animals were anaesthetized and then bled by cardiac puncture in presence of heparin. The infected and non-infected red cells obtained by centrifugation were laked in distilled water and repeatedly washed till free from haemoglobin. The residue was kept under ethanol till sufficient was available for extraction of pigment. This extraction was carried out as described by Rimington \& Fulton (1947), using a concentrated solution of phenol prepared by adding $10 \mathrm{ml}$. water to $90 \mathrm{~g}$. of crystalline phenol. The pigment-containing material was mixed at room temperature with twice its 
volume of the $90 \%$ phenol solution, and was frequently shaken during a period of several hours. The process of extraction was repeated till the absorption band at $627 \mathrm{~m} \mu$. was faint or absent. The combined phenol extracts were then mixed with twice their volume of ethanol and filtered through a no. 4 sintered glass funnel to remove precipitated protein. The solution was then dialysed against tap water in a cellophan bag and the contents, which separate into two layers, were frequently mixed. Some stringy material appeared at this time but contained only small amounts of pigment and was not further investigated. Dialysis was continued against distilled water till turbidity occurred in the coloured layer or till its volume was markedly decreased. On mixing this coloured layer with a large volume of water a fine precipitate was produced. The latter was collected by centrifugation and washed repeatedly in distilled water and finally dried in vacuo. It was noteworthy that the washed red cells containing $\boldsymbol{P}$. berghe $i$ were very much paler than a corresponding volume of material containing $\boldsymbol{P}$. knowlesi or $\boldsymbol{P}$. gallinaceum and furnished much less pigment than the last two samples. Difficulty is frequently experienced in observing the pigment of some strains of $\boldsymbol{P}$. berghei in stained smears of blood, but in that at present employed it was more abundant and as stated by the original authors 'on peut distinguer dans le cytoplasme des grains très fins d'un pigment noir'. In gametocytes it occurs in smaller grains and is more widely scattered as shown in Pl. 1. The photomicrographs of the malarial parasites were recorded on Barnet Orthochromatic plates, employing a Leitz $2 \mathrm{~mm}$. 1.4 N.A. oil immersion apochromatic objective, and a Leitz projection ocular. A Wratten no. 45 filter was used to obtain maximum contrast.

\section{Chemical examination of the residue after dialysis}

A small quantity of the residue was dissolved in $0.01 \mathrm{~N}-\mathrm{NaOH}$ and one-fifth of its volume of pyridine was added followed by a little sodium dithionite. The spectrum of pyridine haemochromogen appeared (band $557 \mathrm{~m} \mu$.). The remainder of the residue was subjected to the Grinstein (1947) procedure for the isolation of protoporphyrin ester from haemoproteins. The crystals obtained had m.p. $219^{\circ}$ (uncorr.) and absorption maxima in chloroform 631.2, $576 \cdot 7,540 \cdot 4,503.9 \mathrm{~m} \mu$. and appeared to be identical in all respects with protoporphyrin IX dimethyl ester. The original pigment is thus identified as haematin.

\section{Comment}

The amount, appearance and location of pigment in different species of malaria parasites and in different developmental forms of the same parasite show wide variations. The effect on the host cell also differs. In human infections the enlarged pale cell in $P$. vivax infections in which fine yellowish brown pigment is formed contrasts with the normal appearance of the red cell and the presence of abundant coarse dark pigment in infections with $\boldsymbol{P}$. malariae. Because of the apparent anomaly in the case of the latter parasite regarding the appearance of the red cell and the amount of pigment formed, some authors have found it difficult to accept that the pigment arises from the 
Journal of General Microbiology, Vol. 8, No. 1

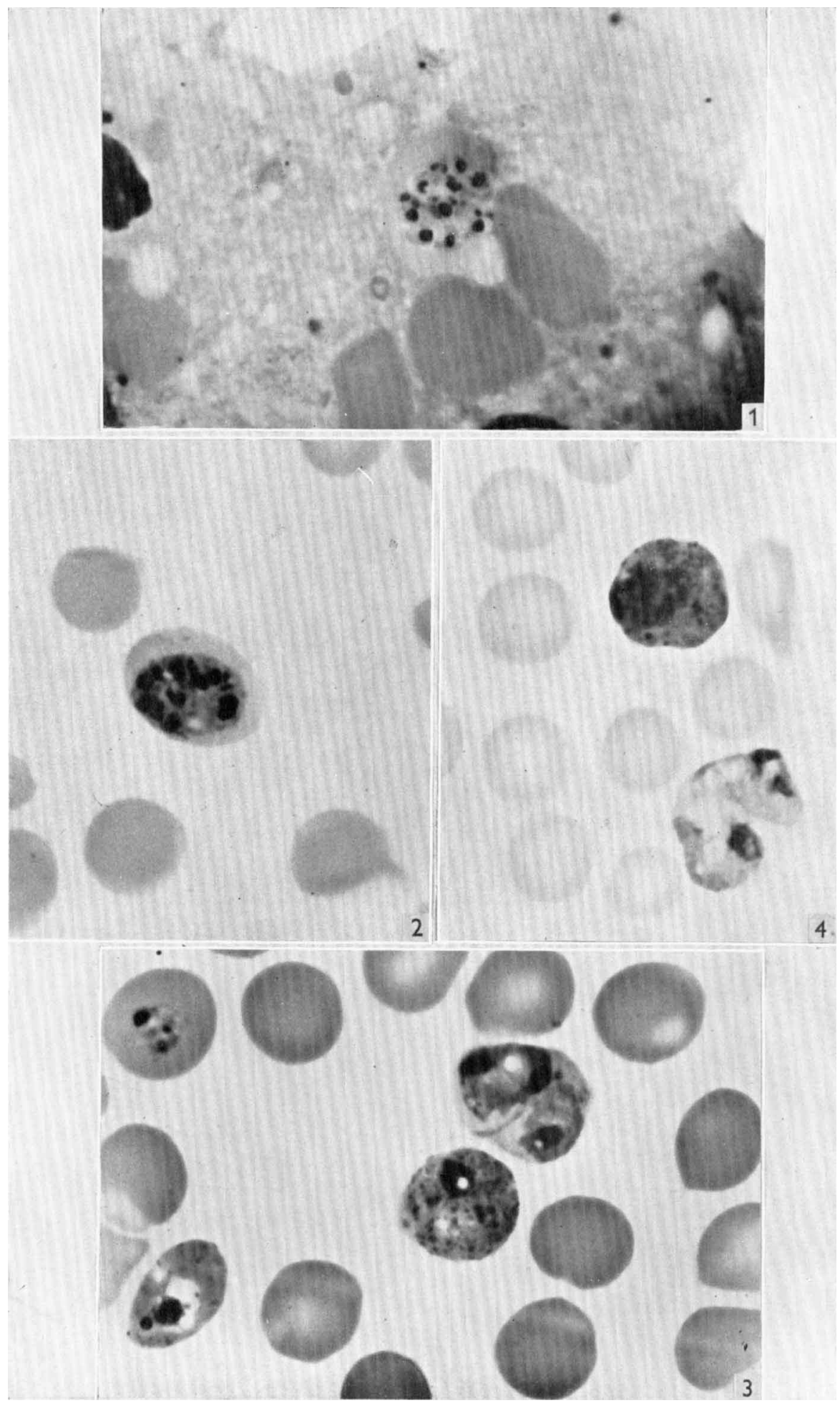

J. D. Fulton \& C. Rimington-Malaria pigment. Plate 1 
haemoglobin of the host cell. In some strains of $\boldsymbol{P}$. berghei the pigment is frequently difficult to detect; the original authors described it as dark and in very fine granules. In certain monkey and fowl parasites the pigment is characteristic. In all malaria parasites so far examined the material has been shown to be haematin.

Acknowledgement is made to Dr J. E. Falk for help in isolation of the protoporphyrin, and to Mr M. R. Young for the photomicrographs.

\section{REFERENCES}

Brown, W. H. (1911). Malaria pigment (so called melanin): its nature and mode of production. J. exp. Med. 13, 290.

Devine, J. \& Fulton, J. D. (1941). Observations on the nature of the malarial pigment present in infections of monkeys (Macacus rhesus) with Plasmodium knowlesi. Ann. trop. Med. Parasit. 35, 15.

Devine, J. \& Fulton, J. D. (1942). The pigment formed by Plasmodium gallinaceum Brumpt, 1935, in the domestic fowl. Ann. trop. Med. Parasit. 36, 167.

Ghosh, B. N. \& Sinton, J. A. (1934). Part II. The reaction of haemozoin to tests for iron. Rec. Malar. Surv. India, 4, 43.

Grinstein, M. (1947). Studies on Protoporphyrin. VII. A simple and improved method for the preparation of pure protoporphyrin from haemoglobin. J. biol. Chem. 167, 515.

Morrison, D. B. \& Anderson, W. A. D. (1942). The pigment of the malaria parasite. Publ. Hlth. Rep., Wash. 57, i, 90.

Rimington, C. \& Fulton, J. D. (1947). The pigment of the malaria parasites Plasmodium knorvlesi and Plasmodium gallinaceum. Biochem. J. 41, 619.

Sinton, J. A. \& Grosh, B. N. (1934a). Studies of malaria pigment (haemozoin). Part I. Investigation of the action of solvents on haemozoin and the spectroscopical appearances observed in the solutions. Rec. Malar. Surv. India, 4, 15.

Sinton, J. A. \& Grosh, B. N. (1934b). Part III. Further researches into the action of solvents and the results of observations on the action of oxidizing and reducing agents on optical properties and on crystallization. Rec. Malar. Surv. India, 4, 205.

ViNCKE, I. H. \& LiPS, M. (1948). Un nouveau plasmodium d'un rongeur sauvage du Congo, Plasmodium berghei n.sp. Ann. Soc. belge Méd. trop. 28, 97.

\section{EXPLANATION OF PLATE}

Fig. 1. Schizont of $\boldsymbol{P}$. berghei from hamster bone marrow showing deeply stained chromatin and large granules of lighter pigment scattered throughout the cytoplasm. $\times 2250$.

Fig. 2. Schizont of $\boldsymbol{P}$. berghei from rat blood showing finer pigment granules than that from hamster. $\times 2250$.

Fig. 3. Female gametocyte of $P$. berghei from hamster blood showing abundant fine pigment granules and small peripheral nucleus. Three other infected cells present. $\times 2250$.

Fig. 4. Male gametocyte from rat blood with abundant pigment granules throughout the cytoplasm and large deeply stained nucleus. A doubly infected red cell is shown below it. $\times 2250$. 